\title{
Assessment of Two-spotted Spider Mite (Tetranychus urticae) on Potato (Solanum tuberosum L.) in Eastern Hararghe, Ethiopia
}

\author{
Gebissa Yigezu, Mulatu Wakgari, Muluken Goftishu
}

Plant Science, College of Agriculture and Environmental Science, Haramaya University, Haramaya, Ethiopia; P.o .Box 138, Dire Dawa, Ethiopia

Corresponding author email:yigezugebissa@gmail.com

\begin{abstract}
Potato is an important tuberous vegetable crop in Ethiopia. However, its production is constrained by arthropod pests, nutrient depletion of soil and diseases. Among arthropod pests, two-spotted spider mite (TSSM, Tetranychus urticae) is one of the major arthropod pests affecting potato production and contributing to low yield in eastern Hararghe, Ethiopia. To tackle this problem, the survey was undertaken to assess the distribution, farmers' management practices and their perception of TSSM on the irrigated potato. The data were collected from ninety-six potato producers during the dry season in Haramaya, Kombolcha, Kersa, and Metta districts of Eastern Hararghe Zone by interviewing, observing and recording from October to March in 2018/2019. The meteorological data were obtained from the National meteorological agency, Jijiga station. The number of TSSM/potato plants, prevalence, incidence and severity levels of potato were analyzed using three-stage nested design. Farmers' perceptions and practices were analyzed by using descriptive statistics, while the relationship of weather factors and altitude with the status of TSSM was analyzed using SPSS software program version 16.0 and determination of Pearson correlation was done using SPSS statistical software. This assessment confirmed that TSSM was found in all the districts with variation in number per potato leaves, incidence and severity levels. The highest incidence (37.88\%), severity (3), number of TSSM/potato (39) per plant was scored from the Haramaya district and the lowest was recorded from Kombolcha district. Based on the observation and response of the respondents, the TSSM was mostly prevailed in autumn (44.79\%) but was the lowest in spring seasons (6.25\%). It severely affected potato production at flowering stages (44.2\%). But the lowest damage was at the seedling stage (7.4\%). The number, prevalence, incidence and severity of TSSM was the highest in Haramaya and the lowest in Kombolcha districts. Data on farmer's perception also showed that $60 \%$ of them recognized TSSM on potato plants. The linear correlation coefficient indicated that the incidence $(r=-0.546, Y=-0.548 X+38.7)$, number of TSSM/potato plant $(r=-0.847, \quad Y=-0.06 .232 X+38.24)$ and severity level $(r=-0.431, \quad Y=-$ $0.0221 X+2.805)$ was decreased as rainfall intensity increased. The studies suggested that the provision of a resistant variety of potato, chemical pesticides, water supply will help the farmers to increase the production and productivity of potato by decreasing the yield losses due to TSSM. Further research on the seasonal abundance, effect of microclimate, natural enemies and management practices on the population dynamics of TSSM in the major potato growing areas of the eastern part of Ethiopia was suggested from the study.
\end{abstract}

Keywords-Assessment, Correlation, Farmers Perceptions, Incidence, Prevalence, TSSM.

\section{INTRODUCTION}

Potato (Solanum tuberosum L.) belongs to the family of Solanaceae; an important tuberous vegetable crops in the world that ranked fourth in the volume of production after rice, wheat and maize. It ranked first among the root and tuber crops, followed by cassava, sweet potato and yam (FAO, 2010).

In Ethiopia potato is important for securing the food demand of the country within a short period of time, cash income, jobs for potato grower and provides high energy, quality protein, substantial vitamins and minerals (Kuarabachew et al., 2007; FAO, 2008).

The low potato yield could be attributed to a number of factors including arthropod pests, nutrient depletion of soil and diseases. Arthropod pests and pathogens caused yield losses of potato up to $17.2 \%(8.1-21.0 \%)$ globally (Savary et al., 2019). Insect pests account for $16 \%$ of yield losses of potato worldwide. It reduced potato tuber yield and quality that could be estimated between $30-70 \%$ (Giordanengo et al., 2013). In tropical countries, the potato 
yield loss caused by arthropod pest was higher and approaching 60-70\% (Nwilene et al., 2008).

In Ethiopia, the most serious and commonly reported arthropod pests that limit potato production were twospotted spider mites (Tetranchus urticae), cutworm (Agrotis ipsilon, A. segetum), white grub (Brahmina coriacea), potato tuber moth (Phthorimaea operculella) alone caused yield loss of potato up to $42 \%$ and $8.7 \%$ in-store and in the field, respectively (Tekalign et al., 2015). Two-spotted spider mites are the most common pests found in potato growing areas of eastern Hararghe, Ethiopia (Muluken et al., 2016). The adults, nymphs and larvae of TSSM feed mostly on green parts of potato leaves leading to its complete destruction and yield during its heavy infestations, as well as potato tuber sprouts and shoots. As a result, farmers continue to bear huge losses due to these pests. Since potato is an important food security crop and its low production brings an impact on national food security.

Understanding potato production constraints, particularly arthropod pests and farmers 'methods of managing TSSM could be useful in designing an effective integrated pest management (IPM) strategy in a sustainable manner. Smit and Matengo (1995) and Obopile et al. (2008) reported that assessing farmers' perceptions of crop production constraints has been used as a tool for documenting pest status and designing suitable pest management options for a particular community. Furthermore, integrating farmers' perspectives of insect pest management by crop entomologists helps the community for the intervention of the local control measure. For example, understanding of farmer's selection criteria of potato varieties might differ from that research scientists had normally assumed. Nonetheless in eastern Hararghe, there is inadequate information on farmers' knowledge, perceptions, and practices in the management of TSSM. Thus, this hindered the development of effective pest management approaches for smallholder farmers. In addition, there is also insufficient information on TSSM status in eastern Hararghe, Ethiopia. Therefore, this research was initiated with the objective of assessing the status of two-spotted spider mite on potato production in selected districts of eastern Hararghe, Ethiopia

\section{MATERIALS AND METHODS}

\section{Description of the study Area}

The survey was conducted in Eastern Hararghe Zone, Oromia National Regional State of Ethiopia on irrigated potato from October to March in the 2018-2019 cropping season. The study area included four major potato producing districts purposely. The selected districts were Haramaya, Metta, Kersa and Kombolcha. From each district, four major potato producing farmer associations were selected. In each farmer association, six respondents, who own potato plant and live along with their family member, were considered. The respondents' farm site was 2-4 kilometers far apart. To avoid any potential bias, the purpose of the survey was made clear for the respondents to enable them to provide the required information. The assessment was made on farmers' perceptions, stage of TSSM prevalence, infestation levels, the season of occurrence, factors favoring the pest development, management practices and severity at farmer's levels on the potato plants. Each site of the district was geo-referenced. Coordinates were mapped using Arc View 10.4 software to show the site spot of the TSSM distribution of TSSM. The meteorological data were obtained from the national meteorological agency, Jijiga stations (Table 1). During the study, potato plants were examined visually aided with magnifying glasses and the sampled leaves of the potato plant was transported to the plant protection research laboratory of Haramaya University to count the number of TSSM by stereomicroscope.

\section{Assessment of Two Spotted Spider Mites (TSSM)}

Twenty-four potato farms were selected per district to assess the distributions, infestations, incidence and damage level of two-spotted spider mites. In each potato farm, three potato leaves from ten potato plants were taken randomly to identify whether TSSM was present or absent across a farm in a zigzag manner. The specific potato plant was located by thrown quadrants. The data were recorded based on visual observations by using a simple 10x hand lens, faceto-face structured interview and observations. In a potato farm where TSSM was incident, the number of adults per leaf was counted to determine the number of TSSM per plant. The average of TSSM per potato-sampled leaves was recorded. The prevalence percentage of TSSM per district was calculated as follows

Prevalence

Number of fields in FA in which TSSM was found $* 100$ Total number of FA $(\mathrm{n}=6)$

Where: FA-Farmers association

Incidence $(\mathrm{PI})=\frac{\text { Numberofinfestedplants }}{\text { Totalplantobserved }} \times 100$, followed by the work of Kataria and Kumar (2012).

The counted TSSM adult was used to determining the infestation, prevalence, severity and incidence levels on potato plants. The mite infestation level was classified according to the following criteria: none: no spider mites present; light: spider mites found on occasional plants, one to 10 per leaf, some leaf damage (russeting, bronzing, speckling) present; medium: 11 to 50 spider mites per leaf present on numerous plants, leaves speckled, mottled yellow or red; and heavy: more than 50 spider mites per potato plant leaves on most plants, many leaves reddishbrown in color followed the work of Steinkraus et al. 
(2003), while the severity index was calculated followed by the work of Kataria and Kumar (2012).

Severity index $(\mathrm{SI})=$ Sum of total grade points $(1-5$ infestation grade G-I to G-V, respectively) of the infested plants / Total number of infested plants observed. It was scored by using 1 to 5 -grade level ( $1=$ no severity; $2=$ up to $25 \%$ severity; $3=25-50 \%$ severity; $4=51-75 \%$ severity and $5=$ higher than $75 \%$ severity).

Table 1 Means of Agro-meteorological features of districts that includes rainfall, temperature, relative humidity and altitudinal ranges in 2018/2019 cropping year

\begin{tabular}{lllll}
\hline Parameter & Kersa & Metta & Haramaya & Kombolcha \\
\hline Average Rainfall(RF)(mm) & 71.72 & 85.58 & 66.58 & 104 \\
Temperature $\left({ }^{\circ} \mathrm{C}\right)$ & $9-26.2$ & $8.5-25$ & $10.8-25$ & $10.5-23$ \\
Relative humidity $(\%)$ & $15.38-41.27$ & $14.4-44.1$ & $14.9-42.8$ & $13.38-44.27$ \\
\hline
\end{tabular}

Obtained from: Ethiopian Meteorological Agency, Jigjiga branch, 2018/2019

\section{Data analysis}

The number of TSSM/potato plants, prevalence, and incidence and damage levels of potato were analyzed using a three-stage nested design following the work of Kumlachew et al. (2016). Data were subjected to analysis of variance (ANOVA) using SAS version 9.0 software package (SAS, 2002). Means were separated using Tukey's test. Farmers' perceptions and practices were analyzed and compared by using descriptive statistics, while the relationship of weather factors with the status of TSSM was analyzed using SPSS software program version 16.0 and determination of Pearson correlation was done using SPSS statistical software.

\section{RESULTS AND DISCUSSIONS Assessment of TSSM on Potato plants}

The two-spotted spider mite distribution and intensity varied across the assessed potato growing districts of eastern Hararghe Zone, Ethiopia. In all the surveyed districts, the TSSM infested the irrigated potato farms (Figure 1). The recording of TSSM on potato plants indicated various degrees of severity. All the surveyed areas showed low to high TSSM infestation levels. During the survey of TSSM, there were also free potato farms recorded in each district (Figure 2). It was highly distributed on the young opened leaves compared with the old leaves of potato-based on the observations. Additionally, two-spotted spider mite densities were higher in potato fields adjacent to dusty roads than potato fields adjacent to asphalt roads. The TSSM also thrived on a wide number of other alternate cultivated and wild host plants, mostly Solanaceae (Datura stramonium, Solanum indicum, $S$. nigrum, and $S$. lycopersicum), Malvaceae, Fabaceae, Cucurbitaceae and Asteraceae families where the agro-ecological conditions are suitable for potato growing. As far as the current distribution of the TSSM is concerned, all the potato growing kebeles in the surveyed areas were already infested. The discussants in Haramaya disclosed that they observed the infestation of their potato for the first time in 2014 and 2015. They also said that they had never ever seen such kind of problem in their potato farm before and commonly called it "Machure" which means pests causing diseases to potato plants. As per the discussant farmers, the TSSM was less in number during the rainy period. 


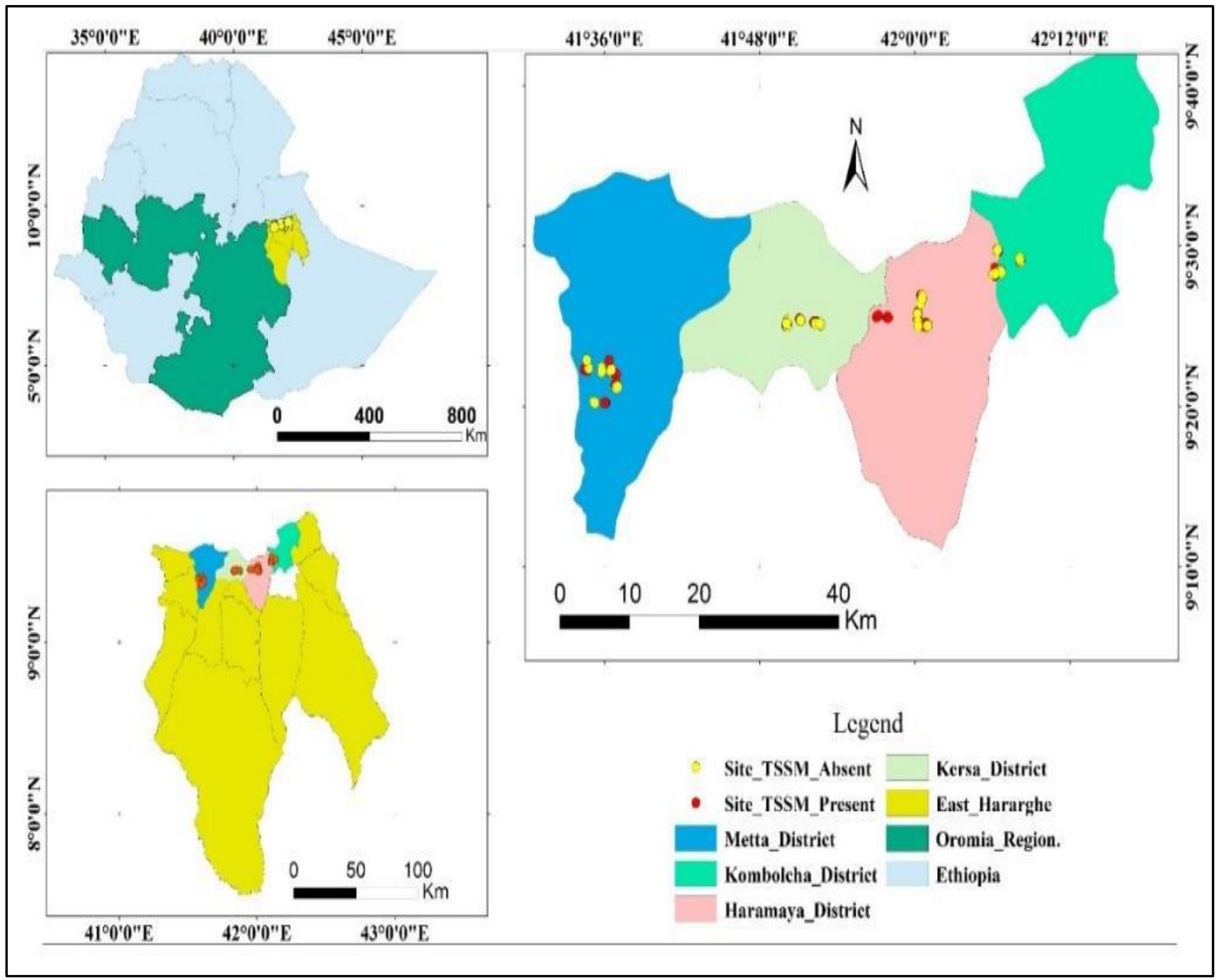

Fig.1: Map of distribution of TSSM on potato producing areas in Eastern Hararghe Zone, Ethiopia during 2018/2019 cropping season

Table 2 Severity status of TSSM in eastern part of the selected districts of Eastern Hararghe Zone, Ethiopia during 2018/2019 cropping seasons

\begin{tabular}{llll}
\hline Districts & Kebele & Severity index & Severity status \\
\hline Haramaya & Ifa Oromia & 3 & high infestation \\
& Tuji Gebissa & 3 & high infestation \\
& Finkle & 3 & high infestation \\
Dersa & Damota & 3 & high infestation \\
& Ifa jelala & 1 & Low infestation \\
& Handura kosim & 3 & high infestation \\
Meda oda & 2 & Medium infestation \\
Metta & Burka weter & 2 & Medium infestation \\
& Haro kutir-1 & 3 & high infestation \\
& Haro kutir-2 & 2 & Medium infestation \\
Kombolcha & Chelenko lola & 3 & high infestation \\
& Dursitu bilisumma & 1 & Low infestation \\
& Kekalli & 1 & Low infestation \\
& Egu & 1 & Low infestation \\
& Bilisuma & 1 & Low infestation \\
& Kerensa & 1 & Low infestation \\
\hline
\end{tabular}






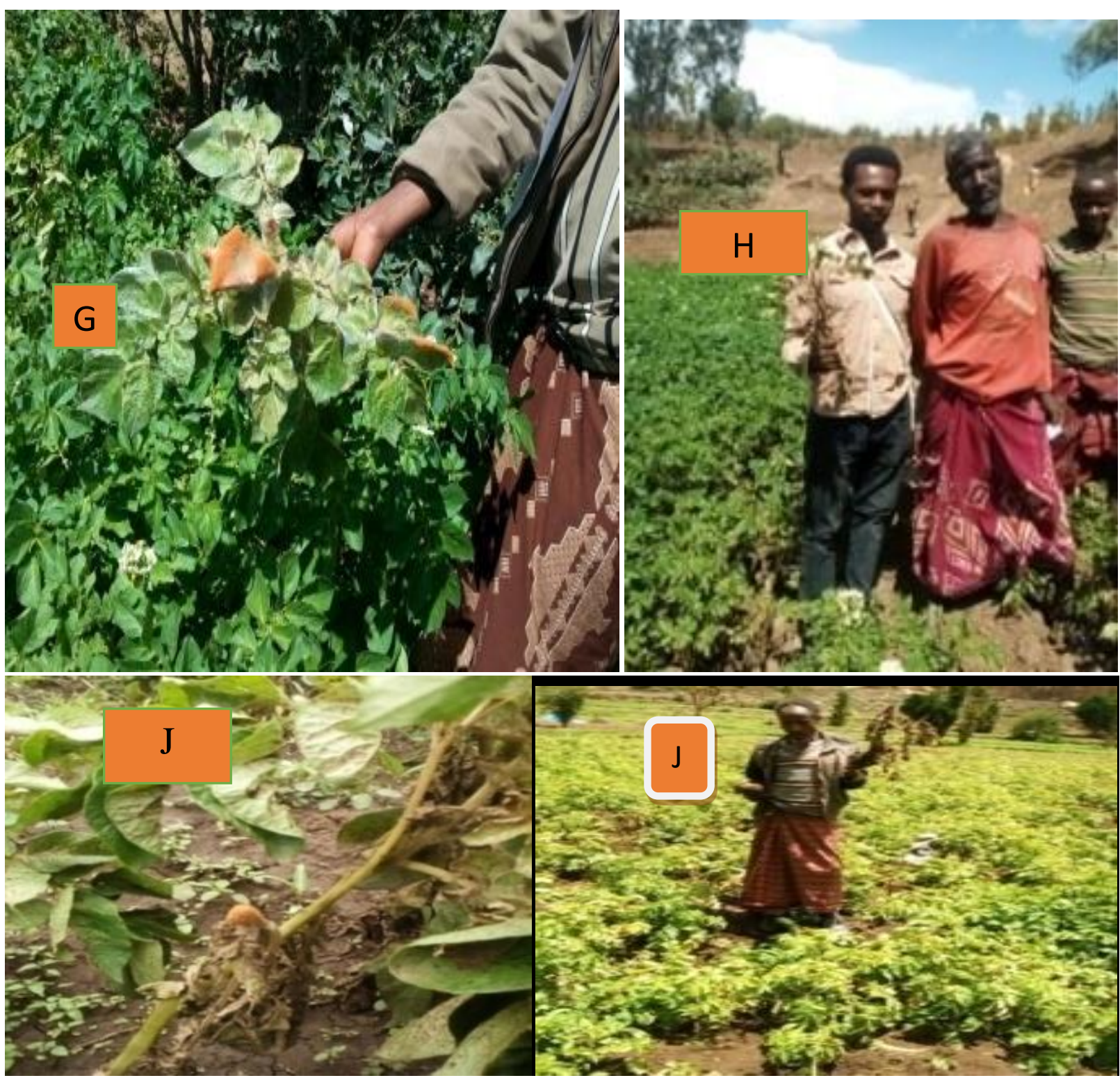

Fig.2 (A-J) Potato farms infested with TSSM in Eastern part of Hararghe Zone, Ethiopia

TSSM was highly infested and severe on potato plant in Haramaya and lower in Kombolcha districts (Table 2). Initially, the TSSM caused yellow mottling but progressively caused scarring, bronzing, and drying out of potato leaves by sucking up the cell contents (Figure 2). The feeding on potato plants is not limited to leaf but also extended to sap contents of green shoots. Thus, the plant photosynthetic ability was reduced that resulted in a decline of overall growth and its yield (Surendra, 2015).

Number of TSSM/potato plant, Prevalence, Incidence and Severity Levels

The incidence of TSSM on potato plant was significantly different across the studied districts (Tukey<0.05). The highest mean incidence level was recorded from Haramaya (37.88\%/potato plant), followed by Kersa (29.6\%/potato plant) and Metta (25.4\%/potato plants). The least incidence level was recorded from Kombolcha districts (7.2\%/potato plants) (Table 3). Similarly, the potato plant severity was significantly different among the districts. The highest mean severity of potato plant was scored from Haramaya (3\%) followed by Kersa (2.4\%) and Metta (2.21\%). The lowest potato plant severity was observed from Kombolcha (1.4\%). The highest number of TSSM/potato plants was counted from Haramaya (39\%), followed by Kersa (27.8\%) and Metta $(24.4 \%)$. The lowest TSSM was recorded from Kombolcha (8.8\%) (Table 6). The present finding was lower than the previous report of Muluken et al. (2016), which indicated that $80 \%$ of potato plant leaves were severely attacked by TSSM. This might be due to the environmental factors such as temperature, rainfall, and relative humidity that was not suitable for reproduction, growth, and development for TSSM in 2018/2019 cropping 
season. As the vegetative or leaf parts of the potato plants were damaged severely, the ability of its biological activity such as photosynthetic activities, uptake of nutrients and water from the soil was reduced. The severely damaged leaves became dry, drop, and covered with webbing, which was produced by protoimmatures, deutoimmatures, and adults. This resulted in a reduction of crop yield as well as aesthetic injuries (Dutta et al., 2012). The highest TSSM prevailed in Haramaya district, while Kombolcha district was the lowest (Table 3).

Table.3: Means of percentage of levels of TSSM per potato plants, its prevalence, incidence, severity and their number per leaves in 2018/2019 cropping season in the selected districts of eastern Hararghe, Ethiopia

\begin{tabular}{lllll}
\hline Districts & $\begin{array}{l}\text { Number of } \\
\text { TSSM/potato plant }\end{array}$ & Prevalence & Incidence & Severity \\
& \multicolumn{2}{l}{} & \\
\hline Haramaya & $39^{\mathrm{a}}$ & $9.733^{\mathrm{a}}$ & $37.88^{\mathrm{a}}$ & $3^{\mathrm{a}}$ \\
Kersa & $27.8^{\mathrm{b}}$ & $6.960^{\mathrm{ab}}$ & $29.6^{\mathrm{ab}}$ & $2^{\mathrm{ab}}$ \\
Metta & $24.4^{\mathrm{c}}$ & $6.284^{\mathrm{b}}$ & $25.4^{\mathrm{b}}$ & $2.25^{\mathrm{ab}}$ \\
Kombolcha & $8.8^{\mathrm{d}}$ & $2.586^{\mathrm{c}}$ & $7.2^{\mathrm{c}}$ & $1^{\mathrm{b}}$ \\
CV & 20.1 & 24.5 & 25.95 & 30.5 \\
F & 12.4 & 14.11 & 16.62 & 6.89 \\
P & 0.006 & 0.0003 & 0.0001 & 0.0059 \\
Tukey` 5\% & 10.1 & 5.23 & 9.45 & 0.52 \\
\hline
\end{tabular}

Means with the same letter are not significantly different

\section{Farmers Perceptions and Management Practices on Potato TSSM}

Farmers perceived that TSSM prevalence followed seasonal changes in environmental factors such as drought and high temperature in potato growing areas. Most of the farmers $(60 \%)$ identified and understood the TSSMs on potato plants. The majority of the farmers $(70 \%)$ stated that the TSSM was first noticed in the year 2014 on wild Solanaceous plants and highly problematic and became a pest in 2015 on potato, since then it remained to be a problem on horticultural crops. Of the interviewed farmers, more than half of them were not able to manage TSSMs. Most of them also suggested many problems among which lack of resistant improved varieties and lack of chemical pesticides were the most prominent ones.

The main methods used by farmers in managing potato TSSM pests on their farms were cultural practices. Some of them also applied chemical insecticide and fungicides (figure 4). Roughing of infested plants, irrigating weekly and early planting was the cultural management strategies applied by farmers to minimize the potato yield losses by TSSM. Profit, Mitac and Dimethoate are among chemical insecticides mainly used by farmers. This application was varying across the districts that ranged by $3.5-14 \%$ of the households. There was no combination of insecticide, other pesticides and biological management practices implemented at farmers' level in eastern Hararghe, Ethiopia (Figure 4). Early planting was the most common method used to limit the damage caused by TSSM, however, crop rotation and insecticide applications were being used but on a very low scale. On average, $41-87.5 \%$ of the potato grower farmers did not manage TSSM. The use of chemical insecticides was relatively low; being highest in Haramaya followed by Kersa districts and very low in the Metta district (figure. 4). Insecticide application was highest in districts which ranked TSSM as the main arthropod pests damaging potato severely. It was evident that some farmers implemented more than one management strategy to reduce the field infestation of potato by insect pests. Aiming at improving the effectiveness of available management methods is, therefore, desired. The low use of insecticides in potato could partly be due to inefficient inaccessibility, high cost of insecticides which subsistence farmers cannot afford, lack of knowledge about pest biology (of especially TSSM). Many farmers did not know how to manage TSSM. However, farmers who applied insecticides to manage TSSM observed reduced damage. This, therefore, encouraged farmers to apply insecticides three weeks after planting within 10 days in the presence of TSSM. Due to the severity of pest infestation during outbreaks, farmers usually received insecticides from agriculture extension workers or local authorities to spray against TSSM because farmers took the pest seriously. It should be noted, however, that the use of chemical insecticide is not a permanent solution as it can be disastrous to human health due to poor handling and elimination of natural enemies of the pest. Nearly forty percent of the interviewed farmers also considered TSSM as potato diseases and used Ridomil and 
Mancozeb fungicides to manage it. However, economically it was not feasible, since both pests are different in response to the agricultural pesticides. Sixty percent of the interviewed farmers suggested that climate change including rainfall irregularity and increase in temperature heats caused the excessive infestation of TSSMs on potato. In addition, more than $70 \%$ of the farmers mentioned that the shortage of moisture in the soil due to the shortage of water for irrigation and increased temperature increased the rate of infestation levels. The interviewed farmers who recognized TSSM on potato plants indicated that the main cause of its occurrence was shortage of rainfall and moisture in soil.

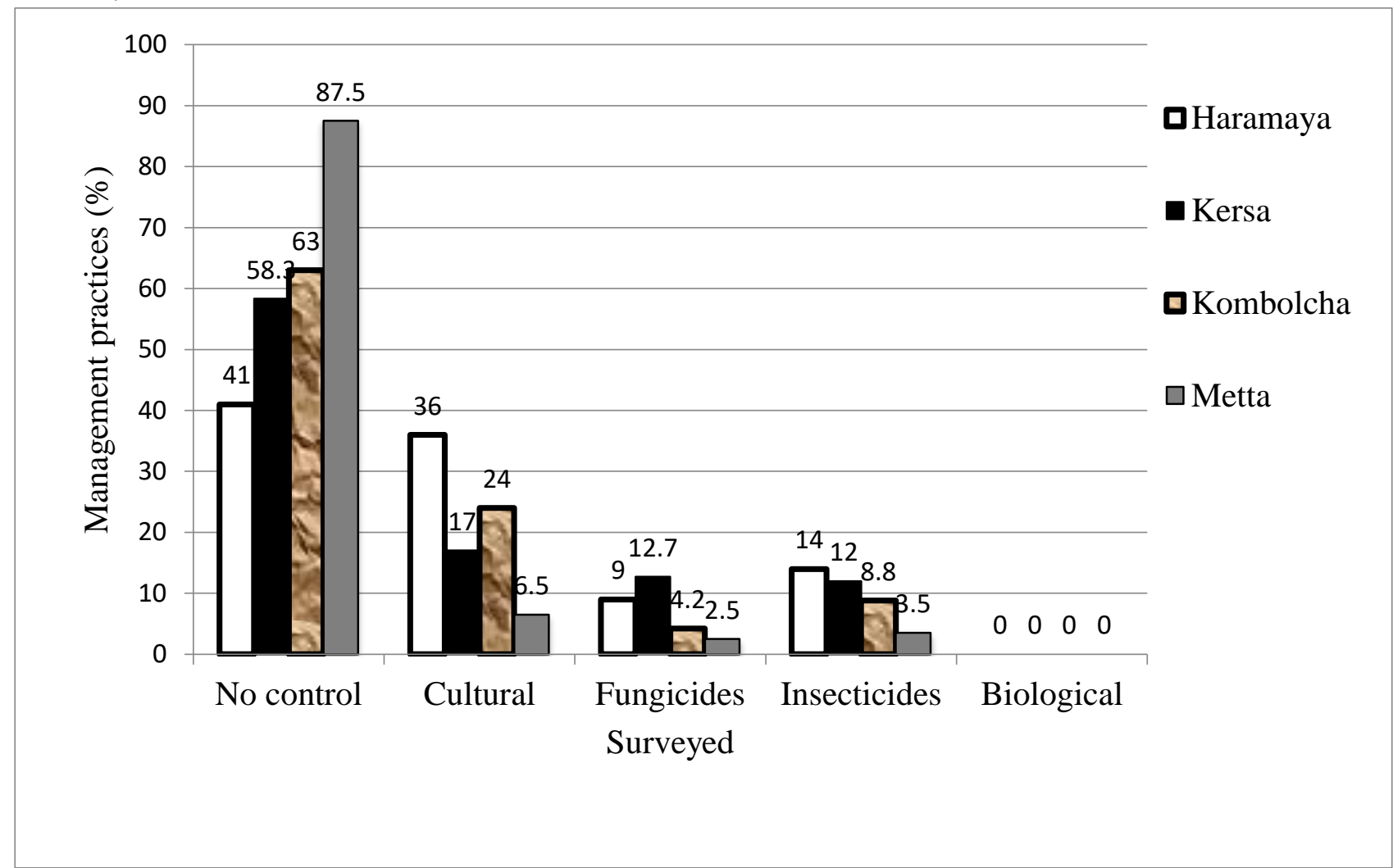

Fig.4: Farmers management practices of TSSMs in potato farm in selected districts of Eastern Hararghe

Based on the observation and response of the respondents, the TSSM mostly prevailed and affected the potato plant during flowering $(44.2 \%)$ stages. The highest prevalence of TSSM on potato plant was during flowering stages, followed by mid $(32.8 \%)$ and maturity $(15.6 \%)$ growth stages, while the least was during seedling (7.4\%) stage (Figure 5). The result was contrary to the finding of Wudil et al. (2016) who reported that TSSM was more attracted and preferred to the young, tender and succulent parts of the potato plants that provide more nitrogen-rich nutrition. The potatoes at the middle to flowering stages are the most vulnerable to mites' infestation. This finding agreed with
Wudil et al. (2017) who reported that the older and the younger plant leaves had inferior nutritive value. This might be why TSSM severity was low at these stages comparatively. The middle leaves of potato hosted more mites than the upper and lower leaves when the nutrient is insufficient. Woods et al. (2007) also reported that the youngest, fully expanded leaves always had more spider mites than young or old leaves. The TSSMs concentrated on the younger leaves than the older ones. These are an indication of the intra and interplant distribution of TSSM to search a more concentrated nutritive young leaves (Woods et al., 2007). 


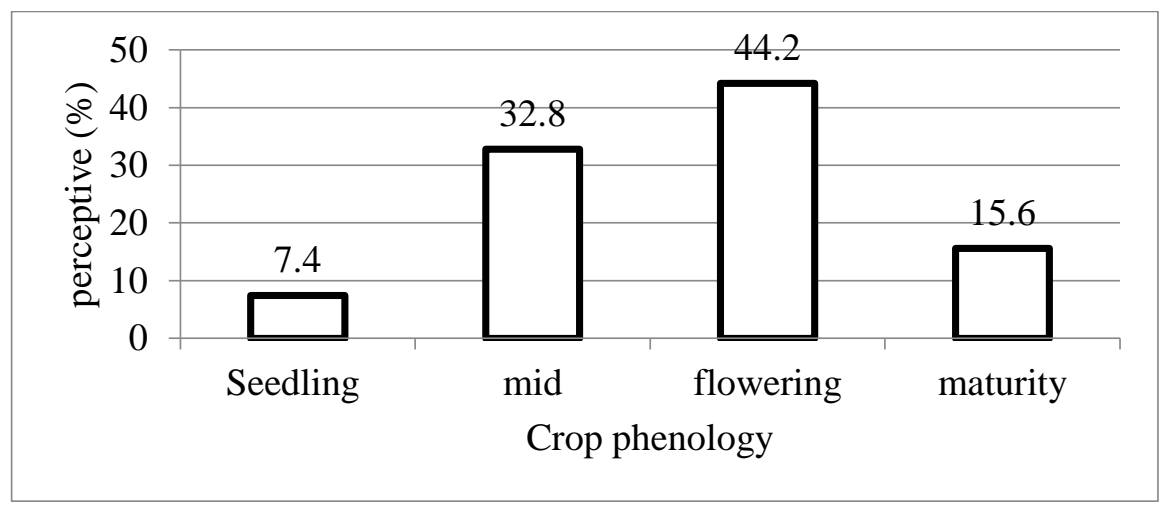

Fig.5: Stages at two spotted spider mites prevalence on potato

Based on the potato producers' perception, the TSSM intensity varied across the season of the year. The highest incident was in autumn (44.79\%), followed by winter (36.46\%), summer (12.5\%) and spring (6.25\%) (Figure 6). Its infestation level was higher on irrigated potato in winter and autumn.

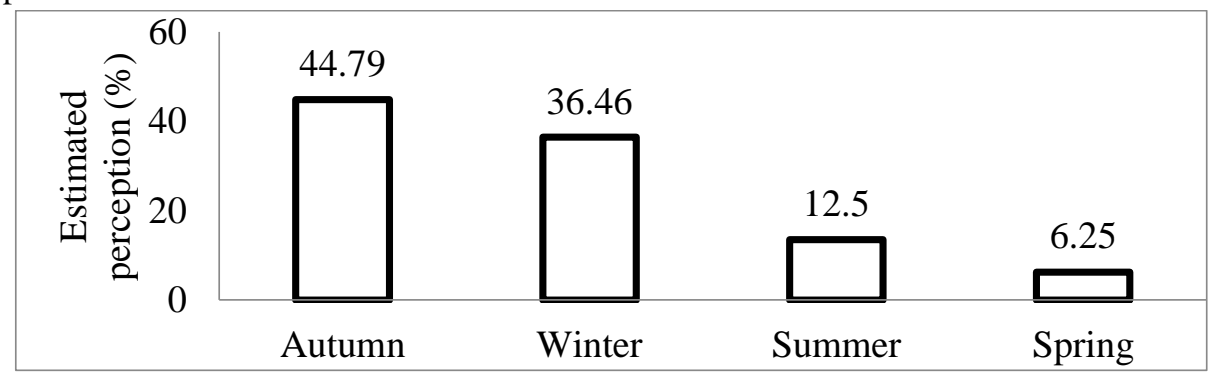

Fig.6: Proportion of farmers' perception on seasonal occurrence of T. urticae on potato plants

These findings agreed with the finding of Ismail et al. (2007) who reported that the TSSMs were lowest in summer than autumn and winter. Wilson and Morton (1993) also reported that populations of TSSM declined through November/December, and then increased progressively thereafter at varying times and rates. Understanding the seasonal abundance and intra-crop distribution of $T$. urticae on plant helps to develop sampling strategies for pest management. In line with this study, Shanbaky et al. (2016) reported that understanding the seasonal prevalence of T. urticae, which varied between seasons helps strongly to influence TSSM. The survival strategy of $T$. urticae appears crucial in determining the extent to which this potential is realized. T. urticae was more abundant on the edges of fields than in the interior in its early occurrence, which indicates colonization from an external source. The edge effect diminished with time, suggesting a lack of continuous colonization. The only exceptions to this pattern occurred when $T$. urticae migrated from other alternate sources including $D$. stramonium and $S$. indicum from nearby potato fields.

\section{Influence of weather factors on TSSM}

More than $60 \%$ of the respondents indicated that TSSMs was more abundant in February-May on the irrigated potato. The linear correlation coefficient indicated that the incidence $\quad(r=-0.546, \quad Y=-0.548 X+38.7), \quad$ number of
TSSM/potato plant $(\mathrm{r}=-0.847, \mathrm{Y}=-0.06 .232 \mathrm{X}+38.24)$ and severity level $(\mathrm{r}=-0.431, \mathrm{Y}=-0.0221 \mathrm{X}+2.805)$ considerably decreased as rainfall intensity increased. This result indicated that the population of TSSM changed as the environmental conditions across seasonal factors changed including the availability of suitable host plants, high temperature, low rainfall and relative humidity in months and years (Table 4). The TSSM prevalence was intensified across eastern Ethiopia resulting in heavy potato yield losses particularly in 2014 and 2015. It was speculated that changing climate conditions increased the outbreak of TSSM, especially under drought conditions. The data demonstrated that the relationship between climate variables (temperature, relative humidity and precipitation/rainfall) and the status of TSSM during 2018/2019 was inseparable.

The development and incidence of the insect pest were much dependent upon the prevailing environmental conditions such as temperature, relative humidity and rainfall (Woiwod, 1997). The timing of pest insect attacks can vary greatly from region to region and from year to year (Collier and Finch, 2001). The data indicated that the decreasing rainfall intensity, relative humidity and increasing temperature might have contributed to increase in the level of incidence, severity, and number of TSSM on potato growing areas of eastern Hararghe (Table 4). The 
density of the incidence and severity levels of TSSMs on potato plant varied across the districts, which was relatively lower in Kombolcha. The TSSM population increased in drought season because of accelerated movement to adjacent plants.

Orellana (2014) reported that TSSM density increased during warmer temperatures under dryer weather conditions. If there were no favorable environmental conditions, the potato can tolerate higher spider mite densities without suffering yield loss, especially when weather conditions do not induce any stress on potato plants. This is because mites prefer to thrive in hot and dry environmental conditions. Temperature is influencing the temporal and spatial distribution of mites in the field because it strongly affects its population growth (Gotoh et al., 2010). It was confirmed that the TSSM population density, decreased as rainfall and relative humidity increased. The TSSM prefers, low relative humidity, high temperature and low rainfall for distribution to cause severe incidence.

Table 4 Correlation co-efficient between the TSSM and weather parameters

\begin{tabular}{|l|l|l|l|l|}
\hline Environmental parameter & & $\begin{array}{l}\text { Correlation } \\
\text { co-efficient }\end{array}$ & $\begin{array}{l}\text { Coefficient } \\
\text { determination }\end{array}$ & Regression equation \\
\hline Average Temperature $\left({ }^{\circ} \mathrm{C}\right)$ & Maximum & 0.576 & 0.332 & $\mathrm{Y}=0.475 \mathrm{x}+18.22$ \\
\cline { 2 - 5 } & Minimum & -0.671 & 0.451 & $\mathrm{Y}=-0.001 \mathrm{x}+21.53$ \\
\hline Average relative humidity $(\%)$ & Maximum & -0.849 & 0.721 & $\mathrm{Y}=-0.251 \mathrm{x}+52.65$ \\
\cline { 2 - 5 } & Minimum & 0.669 & 0.448 & $\mathrm{Y}=5.353 \mathrm{x}+52.65$ \\
\hline Average monthly rainfall $(\mathrm{mm})$ & Maximum & -0.6 & 0.360 & $\mathrm{Y}=-7.784 \mathrm{x}+62.51$ \\
\hline
\end{tabular}

The TSSM the population was higher on water-stressed than well-irrigated plants on the farmer's field based on observations. This finding indicated that environmental factors and pest populations were inseparable. This finding also agreed with previous reports that indicated increasing temperature had significant positive correlation, where relative humidity and rainfall had a significant negative correlation with two-spotted spider mite population in relativity (Manian et al., 2014).

The feeding and reproduction capacity of the TSSM increased under high temperature with low relative humidity (Pakyari and Enkegaard, 2012). In addition, the incubation period of $T$. urticae increased with decreasing temperature and total time taken for completing the life cycle decreased with increasing temperature (Paramjit et al., 2017). The current study also confirmed that the TSSM increased following the drought conditions, including increasing temperature, decreasing rainfall and relative humidity in eastern Ethiopia (Table 4). Eastern Hararghe zone is characterized by a lower amount of rainfall, low relative humidity and maximum temperature followed by the Elino in the 2014-2015 cropping year. These assumptions might lead us to imagine them as the cause of T. urticae outbreak in 2014 on the potato. The population density reached a peak in 2014 and 2015 and caused significant yield losses of potatoes (Muluken et al., 2016). The outbreak and yield loss were inseparably linked to changes in weather conditions of the zone. Drier conditions might have encouraged the survival, perpetuation and distribution of potato TSSMs. Conversely, after 2016 the population and its incidence level decreased.

Rainfall exerted its kinetic energy to strike the TSSM washing off from plant shoots and even killed them. The high relative humidity and low temperatures resulted in the delaying of the growth and development of the mite population in the rainy season (Wudil et al., 2016). In line with this, Wudil et al. (2017) and Barbar et al. (2006) also reported that the altitudinal differences of the agroecologies influence the rainfall distribution, temperature and relative humidity. The temperature, relative humidity and rainfall are important environmental factors that affect the population dynamics of arthropods in agro-ecosystems (Wudil et al., 2016; Prischman et al., 2005). Overall, when the rainfall intensity, temperature and relative humidity increased the incidence, severity levels and the number of two-spotted spider mites was negatively affected (Table 4). In line with this study, TSSMs were positively influenced by increasing temperature and negatively affected by increasing rainfall intensity (Wudil et al., 2017).

\section{SUMMARY AND CONCLUSIONS}

T. urticae is the potato production constraint under favorable dry weather conditions. It causes devastating yield losses unless proper management techniques are developed to mitigate the problem during favorable weather conditions. This study, therefore, aimed to assess the distribution, farmers' perceptions and management practices of farmers against $T$. urticae on irrigated potato in four districts of eastern Hararghe zone (Haramaya, 
Kombolcha, Kersa and Metta). The attempt was also made to relate, the TSSM distribution, incidence, severity and their numbers with weather factors in the eastern Hararghe zone. The parameters decreased with the increment of rainfall, but increase as temperature increased.

Potato plant was more severely damaged during mid and flowering stages than at seedling and maturity stages. To mitigate this problem, some of the farmers practiced cultural techniques and also applied synthetic chemical pesticides, but nearly $40 \%$ of the respondents were not familiar to the pest as it is new to the environment and considered as plant diseases. The farmers need the integration of using improved resistance varieties, agrochemicals, and water supply for irrigation to tackle the red spider mite problem. Therefore, effective management should focus on understanding the right stages of the plant and the pest as well as prevailing climatic factors to prevent an outbreak. Furthermore, implementing low-cost agronomic practices and other effective technological interventions are suggested for sustainable management of the red spider mite

\section{ACKNOWLEDGEMENTS}

I would like to express my enormous appreciation and heartfelt gratitude to my co-author Dr. Mulatu Wakgari for his systematic planning, guidance, encouragement, valuable suggestions and kind co-operation to complete this research work and in the preparation of the manuscript.

The authors also thank Haramaya University for giving the chance to pursue this work and research grant. The help of my colleagues Ashenafi Kassaye, Megersa Dinsa, Misrache Melesse and Gebi Hussien during data collection and moral support are also appreciated. I'm highly gratitude to $\mathrm{My}$ father Yigezu Wendimu and my mother Kuli Chala as well as my uncle Beyisa Gemechu and Becha Dinsa for their sincere love, concern, encouragement and moral support towards the success of this work. All the above I give thanks and honor to my almighty God for his countless blessings.

\section{REFERENCES}

[1] Barbar, Z., Tixier, M.S., Cheval. B. 2006. Effects of agro forestry on phytoseiid mite communities (Acari: Phytoseiidae) in vineyards in the South of France. Experimental and Applied Acarology, 40:175-188.

[2] Collier, R., H. and Finch, S. 2001. Forecasting attacks by pest insects of cruciferous crops. The management of diamondback moth and other crucifer pests. Proceedings of the $4^{\text {th }}$ International Workshop, 163-168.

[3] Dutta, N. K., Alam, S. N., Uddin, M. K., Mahmudunnabi, M. and Khatun, M. F. 2012. Population abundance of red spider mite in different vegetables along with its spatial distribution and chemical control in brinjal, Solanum melongena L. Bangladesh J. Agric. Res, 37: 399-404.

[4] FAO (Food and Agriculture Organization of the United Nations).2008. International year of the potato. Available: http://www.potato2008.org/en/world.africa.html. [access on August 12, 2018].

[5] FAO (Food and Agriculture Organization of the United Nations).2010. Strengthening potato value chains. Technical and policy options for developing countries. The Food and Agriculture Organization of the United Nations and the Common Fund for Commodities. Rome, Italy.

[6] Giordanengo, P., Vincent, C., Alyokhin, A. 2013. Insect Pests of Potato, Global Perspectives on Biology and Management Elsevier Inc, Wyman Street, Waltham, USA. 633pp. ISBN: 978-0-12- 386895-4.

[7] Gotoh, T., Sugimoto, N., Pallini, A., Knapp, M., Hernandez Suarez, E, Ferragut, F. 2010. Reproductive performance of seven strains of the tomato red spider mite, Tetranychus evansi (Acari: Tetranychidae) at five temperatures. Experimental and Applied Acarology, 52:239-259.

[8] Ismail, M., S., M., Naggar, M., H., Soliman, M., F. M., Mona M. Ghallab. 2007. Ecological studies on the two-spotted spider mite, Tetranychus urticae Koch and its predators, Egyptian journal of natural toxins, 4(2): 26-44.

[9] Kataria, R. and Kumar, D. 2012. Occurrence and Infestation Level of Sucking pests: Aphids on various host plants in Agricultural Fields of Vadodara, Gujarat (India). International Journal of Scientific and Research Publications, 2 (7):1-6.

[10] Kuarabachew, H., Assefa, F., Hiskias, Y. 2007. Evaluation of Ethiopian Isolates of Pseudomonas fluorescens as Biocontrol Agent against Potato Bacterial Wilt Caused by Ralstonia (Pseudomonas) solanacearum, Addis Ababa, Ethiopia. Acta agri. Slov., 90 (2):125-135.

[11] Kumlachew Alemu, Girma Adugna, Fikre Lemessa, Diriba Muleta. 2016. Current status of coffee berry disease (Colletotrichum kahawae Waller and Bridge) in Ethiopia. Archives of Phytopathology and Plant Protection. DOI: 10.1080/03235408.2016.1228736.

[12] Manian, P., Vinoth Kumar, S., Chinniah, C., Muthiah, C. and Sivasubra. 2014. Influence of abiotic factors on two spotted spider mite population in eggplant. Current Biotica. 7(3): 246-250.

[13] Muluken Goftishu, Mashilla Dejene, Ashenafi Kassaye and Tesfaye Belay. 2016. Red Spider Mite, Tetranychus urticae Koch (Arachnida: Acari-Tetranychidae): A Threatening Pest to Potato (Solanum Tuberosum L.) Production in Eastern Ethiopia. Pest Management Journal of Ethiopia, 19:53-59.

[14] Nwilene, F. E.; Nwanze, K. F. and Youdeowei, A. (2008). Impact of integrated pest management on food and horticultural crops in Africa. Entomol. Exp. Appl., 128: 355-363.

[15] Obopile, M.D., Munthali, C., Matilo, B 2008.Farmers' knowledge, perceptions and management of vegetable pests and diseases in Botswana. Crop Prot, 27:1220-1224. 
[16] Orellana Jimenez, Luis 2014. Impact of Early Infestation of Two-Spotted Spider Mites (Tetranychus urticae) on Cotton Growth and Yield. Theses and Dissertations. 1025. http://scholarworks.uark.edu/etd/1025.

[17] Pakyari, H. and Enkegaard, A. 2012. Effect of different temperatures on consumption of two spotted mites, Tetranychus urticae, eggs by the predatory thrips, Scolothrips longicornis. J Insect Sci., 12:98. doi:10.1673/031.012.9801.

[18] Paramjit Kaur, Paramjit Kaur and Frank G Zalom. 2017. Effect of temperature on the development of Tetranychus urticae and Eotetranychus lewisi on strawberry. Journal of Entomology and Zoology Studies, 5(4): 441-444.

[19] Prischman, D.A., James, D.G., Snyder, W.E. 2005. Impact of management intensity on mites (Acari: Tetranychidae, Phytoseiidae) in South central Washington wine grapes. International Journal of Acarology, 31:277-288.

[20] Savary, S., Willocquet, L., Pethybridge, J.S., Esker, P., McRoberts, N., Nelson, A. 2019. The global burden of pathogens and pests on major food crops. Nature Ecology \& Evolution, 3 (3): 430-439.

[21] Shanbaky, Nawal, Helmy, Nadia, El-Erksousy, Mohammed, Ibraheem, Manal. 2016. Seasonal dynamics of the two spotted red spider mite, Tetranychus urticae Koch on two field crops in Qalubyia governorate, Egypt; Egyptian Academic Journal of Biological Sciences. Entomology, 9:15-24 (Accessed 25, 05, 2019).

[22] Smit, N. J.M, Matengo, L.O. 1995.Farmers'cultural practices and their effects on pest control in sweet potato in South Nyanza Kenya. Int. J. Pest Manage, 41:2-7.

[23] Statistical Analysis System (SAS) Institute, Inc. 2002. SAS (R) Proprietary Software Version 9.00 (Ts M0). SAS Institute, Inc., Cary, Nc, USA.

[24] Steinkraus, D., Zawislak, J. Lorenz, G., Layton, B., Leonard, R. 2003. Spider Mites on Cotton in the Midsouth. Spider mite brochure Copy. http://cotton.tamu.edu/Insects/Spider.

[25] Surrendra, K.D. 2015. Efficacy of botanical, chemical, and microbial pesticides on two spotted spider mites and their impacts on predatory mites.

[26] Tekalign, Z., Bayeh, M., Mulugeta, N. 2015. Potato tuber moth, Phthorimaea operculella (Zeller) management using Entomophathogenic fungi on seed potato tuber in West Shewa, Ethiopia. Journal of Plant Sciences, 3: 207- 211.

[27] Wilson, L.J and Morton, R. 1993.Seasonal abundance and distribution of Tetranychus urticae (Acari: Tetranychidae), the two spotted spider mite, on cotton in Australia and implications for management. Bulletin of Entomological Research, 83(2): 291-303.

[28] Woiwod, I. 1997. Detecting the effects of climate change on Lepidoptera. J. Insect Conserv., 1(3): 149 -158.

[29] Woods, J. L., Dreves,A. J., Fisher,G. C., James D. G., L. C. Wright, L.C., Gent, D. H. 2007. Population Density and Phenology of Tetranychus urticae (Acari: Tetranychidae) in Hop is Linked to the Timing of Sulfur Applications. Environmental Entomology, 41:621-635. https://doi.org/10.1603/EN11279 (accessed 25, 05, 2019).
[30] Wudil, B. S., Rwegasira, G. M., Kudra, A. B., Jeremiah, S., 2017. Spatial and Temporal of Cassava Green Mite, Mononychellus tanajoa Bonder (Acarina: Tetranychidae) in Tanzania. Archives of Current Research International, 8(3): 1-13 (Accessed April 7, 2019).

[31] Wudil, B.S., Rwegasira, G.M., Kudra, A.B., Jeremiah, S. 2016. Response of some cassava varieties to Mononychellus tanajoa Bondar. (Tetrachynidae: Acarina) Infestation in the Lake Zone, Tanzania. Journal of Agriculture and Ecology Research International, 7(4):1-9. 